\title{
Surface modification of activated carbon by corona treatment
}

\author{
MATHEUS F.F. PEGO ${ }^{1}$, MARIA LÚCIA BIANCHI ${ }^{2}$, JANAÍNA A. CARVALHO ${ }^{2}$ and TAIS R.L.A. VEIGA \\ ${ }^{1}$ Departamento de Ciências Florestais, Universidade Federal de Lavras, Campus Universitário, \\ Av. Doutor Sylvio Menicucci, 1001, 37200-000 Lavras, MG, Brazil \\ ${ }^{2}$ Departamento de Química, Universidade Federal de Lavras, Campus Universitário, \\ Av. Doutor Sylvio Menicucci, 1001, 37200-000 Lavras, MG, Brazil
}

Manuscript received on November 22, 2017; accepted for publication on April 17, 2018

\begin{abstract}
How to cite: PEGO MFF, BIANCHI ML, CARVALHO JA AND VEIGA TRLA. 2019. Surface modification of activated carbon by corona treatment. An Acad Bras Cienc 91: e20170947. DOI 10.1590/0001-3765201920170947.

Abstract: Surface modification may lead activated carbon (AC) to take on different properties. This study aimed to promote surface modification of activated carbons using corona treatment (electrical discharge). In this study, powdered commercial activated carbon was used. Activated carbons were subjected to corona treatment at different exposure times $(2,5,8$ and $10 \mathrm{~min})$ at $4.5 \mathrm{~cm}$ height from the source. To observe differences promoted by treatment, activated carbons were analyzed by acidity, surface functional groups, Fourier Transform Infrared Spectroscopy (FTIR), elemental analysis (CHN), proximate analysis and thermogravimetry. Corona treatment impacted surface chemistry of activated carbons. There was a trend of increasing surface acidity according to exposure time. There were changes in functional groups, increasing carboxyl acid and decreasing lactone and phenol groups. FTIR analysis showed peaks in the bands at 3500, 1650 and $1300 \mathrm{~cm}-1$. Increase of oxygen content and decrease of carbon content were also found. Immediate analysis followed similar tendency for volatile and fixed carbon content. There were also differences in thermogravimetry analysis. Treated activated carbons were different compared to virgin activated carbon. This difference was performed by surface oxidation. Thus, this study showed that corona treatment caused surface modifications and might impact adsorption process.
\end{abstract}

Key words: chemical reactions, electric discharge, oxidation, surface chemistry.

\section{INTRODUCTION}

Activated carbons are largely used as an adsorbent of several substances due to many characteristics like porosity, surface area and surface chemistry. Although it is a consolidate material, activated carbons need to increase their adsorption capacity, especially for specific adsorbates, and this is possible by surface modifications on their chemical structure

Correspondence to: Matheus Felipe Freire Pego

E-mail: matheusfelipefreire@gmail.com

ORCid: http://orcid.org/0000-0002-3141-1801
(Goscianska et al. 2015). Surface modification can be carried out by chemical substances (Aguiar et al. 2016, Yang et al. 2016), ozone (Jaramillo et al. 2010), nitration (Cao et al. 2014, Shafeeyan et al. 2015), physical methods (Ge et al. 2015, Zhang et al. 2016a), oxidation (Gong et al. 2016, Houshmand et al. 2011) and other methods.

Surface modifications are changes to the surface structure, which mainly involves chemical changes. Surface modification on activated carbon are conducted to cause variations in surface chemistry and consequently on its properties. Also, 
selected surface modifications can be performed for a specific adsorbate (Houshmand et al. 2013, Shafeeyan et al. 2010). Surface modification mainly affects surface chemistry, although it can cause some modifications to the physical properties depending on the treatment to be performed. This is dependent on the methodology used to promote surface modification (Pego et al. 2017).

The modifications of surface chemistry involve modification of surface functional groups. Surface functional groups can be modified by several methods, which lead activated carbon to present different properties. The activated carbon surface can become more acid or basic, polar or non-polar depending on treatments. Surface chemistry is directly related to the adsorption process. Different surface chemistry directly impacts dye adsorptions. In adsorption, the main effect is the relationship of surface chemistry properties (acidity, basicity, polarity) and their interaction with adsorbate properties (Zhou et al. 2015).

Oxidation is the leading way to cause modification on activated carbons. The addition of oxygen atoms can be performed by several methods, whether chemical or physical. Introducing oxygen atoms makes the surface structure more acid and enhances oxygenic surface functional groups (Gong et al. 2016). This affects adsorption properties for a given adsorbate.

Most of activated carbon surface modifications imply addition of some atoms by several ways, which can generate waste that must be treated and discarded after the end of the process. Furthermore, these processes can be expensive and little effective when applied in industries to cause surface modifications. Thus, new surface modification technologies are necessary and have to be improved. One novel technology is the corona treatment, which has been already applied to cause surface modification of polymers and other carbonaceous material.

Corona treatment is a high voltage and frequency electrical discharge that is applied to the surface of some material. This equipment causes surface oxidation through the ionization of gases $(\mathrm{O} 3, \mathrm{O} 2)$ between electrode and substrate by electric discharge, causing covalent reactions on the surface and changes in material properties (Stepczyñska 2015). Recently, corona treatment has been studied by some authors to promote surface oxidation in many materials, changing their properties. However, this treatment has not been used to cause surface modification of activated carbon, although similar treatments are already studies, like plasma treatment and air dielectric barrier discharge. Therefore, the aim of this study was to evaluate the effect of corona treatment (electric discharge) on the surface modifications of commercial activated carbons.

\section{MATERIALS AND METHODS}

In this study, commercial powered activated carbon was used. Activated carbon was produced by Alphacarbo Company. The activated carbon type was Alphacarbo LA from lot 3680.

\section{CORONA DISCHARGE}

Activated carbons were submitted to electric discharge produced by three-dimensional surface corona equipment, Plasma Tech - Corona Brazil, Model PT-1 $0.5 \mathrm{~kW}$ power, $220 \mathrm{~V}$ and frequency of $60 \mathrm{~Hz}$ (Figure 1).

Corona treatment was used to promote surface oxidation of the samples. The samples were put in aluminum box (Figure 1d), which was made aiming towards uniform treatment and avoiding losses during the process, since the activated carbons were in powdered form and the contact with the electric discharge caused losses.

Four corona treatments were used, varying the exposure time of the samples to the discharge. Treatment one (T1) was the standard. Thus, no exposure discharge was done in this treatment. Exposure times of the other treatments were 2, 5, 8 and 10 minutes (T2, T3, T4 and T5, respectively). 
Approximately $2.0 \mathrm{~g}$ of virgin activated carbon were weighed, for each treatment. Head height was established at $4.5 \mathrm{~cm}$. Exposure times and head height was performed according to Carvalho et al. (2017), who used corona treatment as pretreatment in order to improve glucose content in sugarcane bagasse.

\section{SURFACE FUNCTIONAL GROUPS}

Boehm titration was performed to identify the main oxygenated groups of the activated carbons surface. Titration was conducted according to Boehm methodology (Boehm 1994). Titration was performed in a Metrohm potentiometric titrator, model Titrando 888. During the titration $\mathrm{NaOH}$, $\mathrm{Na}_{2} \mathrm{CO}_{3}$ and $\mathrm{NaHCO}_{3}$ were used as reagents. These reagents have different actions in the neutralization of functional groups. A pH meter was used to determine the end point of the titration.

The technique determined the quantity of some functional groups on activated carbon surface. Dry material $(0.25 \mathrm{mg})$ was weighed and added to $10 \mathrm{ml}$ of $\mathrm{NaOH}\left(0.05 \mathrm{~mol} \mathrm{~L}^{-1}\right)$. The material was agitated for $24 \mathrm{~h}$ on a Certomat MO II orbital shaker at 200 $\mathrm{rpm}$. The same process was repeated using $\mathrm{Na}_{2} \mathrm{CO}_{3}$ and $\mathrm{NaHCO}_{3}\left(0.05 \mathrm{~mol} \mathrm{~L}^{-1}\right)$ as reagents. After the agitation period, the solution was filtered through filter paper $\left(80 \mathrm{~g} \mathrm{~m}^{-2}\right.$ grammage, $205 \mu \mathrm{m}$ thickness, $14 \mu \mathrm{m}$ pore). $5 \mathrm{~mL}$ aliquot of filtered solution was removed. In $\mathrm{NaOH}$ and $\mathrm{NaHCO}_{3}$ aliquots, $10 \mathrm{~mL}$ of standardized hydrochloric acid $\left(0.05 \mathrm{~mol} \mathrm{~L}^{-1}\right)$ was added. In the $\mathrm{Na}_{2} \mathrm{CO}_{3}$ aliquot, $15 \mathrm{~mL}$ of the same acid was added. After reagents addition, the samples were placed in a support and left for 2 hours under $\mathrm{N}_{2}$ flow to remove gases that may impact $\mathrm{pH}$ of the samples. The titration was performed in an automatic titrator, with standardized solutions of $\mathrm{NaOH}$ and $\mathrm{HCl} 0.05 \mathrm{~mol} \mathrm{~L}^{-1}$. The amount of acid character sites was calculated according to the turningpoint titration and volumes, concentrations and mass of the adsorbent from titration data.
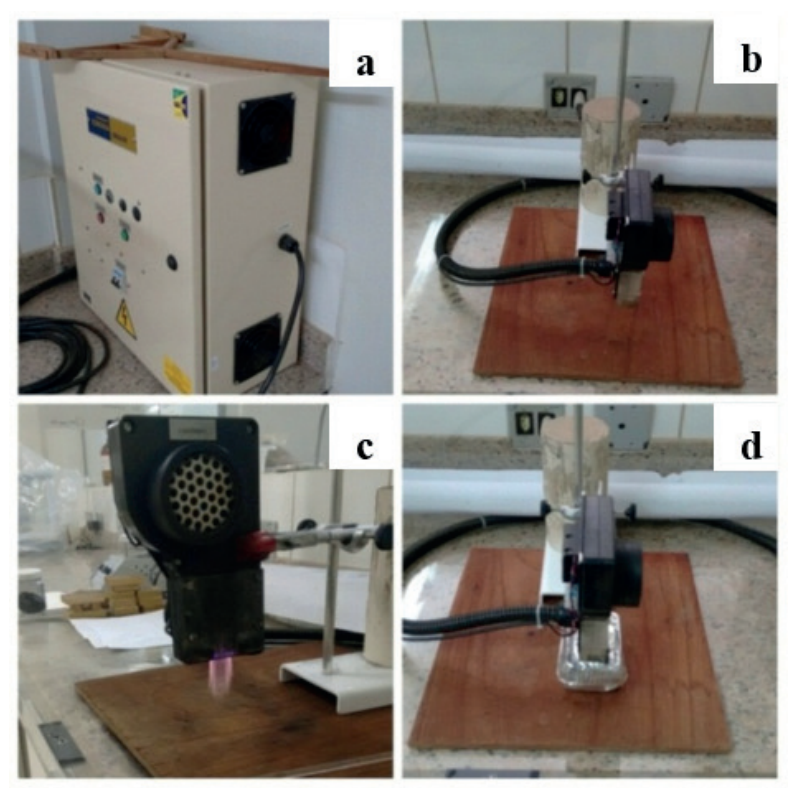

Figure 1 - Corona equipment (a) control box; (b) head; (c) discharging head; (d) surface treatment layout.

FOURIER TRANSFORM INFRARED SPECTROSCOPY (FTIR)

FTIR analyses were performed in IRAffinityShimadzu equipment, spectral range of 400 to 4000 $\mathrm{cm}^{-1}, 4 \mathrm{~cm}^{-1}$ resolution and 32 scans. The samples were prepared in the form $\mathrm{KBr}$ tablets. Thus, $0.0010 \mathrm{~g}$ of each treatment and $0.1990 \mathrm{~g}$ of $\mathrm{KBr}$ were weighed. Reference was a tablet of only $\mathrm{KBr}$.

\section{ELEMENTAL ANALYSIS}

Elemental analysis was carried out on Elementar universal analyzer model Vario Micro cube. This equipment uses carrier and ignition gases, which are, respectively, helium and oxygen. The oxygen quantification was performed through difference of elements. The granulometry of 200-270 mesh was used to perform this analysis. $2 \mathrm{mg}$ of each treatment were weighed and added in a tin capsule and completely incinerated at $1200{ }^{\circ} \mathrm{C}$. Four repetitions were performed.

\section{PROXIMATE ANALISYS}

Proximate analysis was carried out on muffle furnace. Fixed carbon, volatile and ash content 
were determined according to D-1762-64 standard (ASTM 2007). Fixed carbon was determined by difference.

\section{THERMOGRAVIMETRY (TGA)}

The weight loss curves were obtained using a TA$60 \mathrm{WS}-S h i m a d z u$ thermal analyzer. $4 \mathrm{mg}$ (200270 mesh) of each treatment were weighed. The samples were heated to $1000^{\circ} \mathrm{C}, 10^{\circ} \mathrm{C} \mathrm{min}^{-1}$ heating rate under $\mathrm{N}_{2}$ atmosphere at $50 \mathrm{~mL} \mathrm{~min}^{-1}$ flow.

\section{RESULTS AND DISCUSSION}

\section{SURFACE ANALYSIS AND FUNCTIONAL GROUPS}

The study of activated carbon surface chemistry is very important, since for certain applications, a reaction or interaction between adsorbent and adsorbate is necessary. Surface chemistry is related to presence of functional groups on the activated carbon surface and its characteristics.

According to Table I, it is possible to observe that although somewhat variable, there is a tendency in the increase of acidity according to the increase of exposure time to the corona treatment. Thus, can be inferred that surface oxidation occurs, through oxygen atoms insertion and formation of functional groups by means of chemical bonds, modifying surface chemistry of the activated carbons. According to Stepczyñska (Stepczyñska 2015), chemical reactions occurred by exposure to corona treatment promote formation of covalent reactions between atoms of the materials surface and atoms that are incorporated by the treatment, mainly oxygen atoms. Covalent reactions are created over gases ionizations caused by electric discharge.

Surface oxidation is explained by ionization of atmospheric gases that are located between the equipment head and the material surface, causing changes in its properties through chemical reactions. Surface oxidation has already been studied by Brzeziński et al. (2009), Zhang et al.
(2012) and Kostov et al. (2013), who used corona treatment to cause oxidation in Polyester fabrics and Polypropylene, and as results, obtained increased of acidity, polar surface groups, changes in hydrophilicity and functional groups distribution

The quantity of the different functional groups due to treatment is presented in Table II. Generally, the main functional group is carboxylic acid, compared to other functional groups. As well as acidity, there is an increasing tendency in the number of groups formed by carboxylic acid, with increasing exposure time to the corona treatment. This fact may explain the increasing tendency towards acidity, since these groups are strong acids, and are the main constituents of activated carbon acidity. The formation of carboxyl groups, with increased exposure time, is due to surface oxidation, with formation of covalent bonds between carbon from activated carbons and atmospheric oxygen. Also, the exposure time increase may decrease electron density from activated carbon, decreasing the reducing properties of carbons.

For lactone and phenol groups there is a decreasing tendency with the increase of exposure time, except in treatment four (T4). These groups are considered weak acids and, therefore, have less interference in the acid content of the activated carbons. The increasing and decreasing tendency of these functional groups may be related to the chemical reactions that occur during the treatment, modifying the quantity of functional groups through oxidation. As reported, treatment four (T4)

TABLE I

Acidity of activated carbons depending on treatment.

\begin{tabular}{cccc}
\hline \multirow{2}{*}{ Treatment } & \multicolumn{3}{c}{ Acidity $\left(\mathbf{m m o l ~ g}^{-1}\right)$} \\
\cline { 2 - 4 } & $\mathbf{( N a O H})$ & $\left(\mathbf{N a}_{\mathbf{2}} \mathbf{C O}\right)$ & $(\mathbf{N a H C O})$ \\
\hline T1 $(0 \mathrm{~min})$ & 1.0207 & 0.8344 & 0.9855 \\
T2 $(2 \mathrm{~min})$ & 0.9934 & 0.8647 & 0.9889 \\
T3 $(5 \mathrm{~min})$ & 1.0336 & 0.9034 & 1.0261 \\
T4 $(8 \mathrm{~min})$ & 1.0369 & 0.8669 & 1.0153 \\
T5 $(10 \mathrm{~min})$ & 1.0483 & 0.9142 & 1.0305 \\
\hline
\end{tabular}


had a different behavior in quantity of functional groups. This can be related to small amount of carboxylic acid, changes occurred during treatment (porosity) or even problems in Boehm titration. However, some authors found similar tendency during treatment with electric discharge in activated carbon, where functional groups behaved differently with the increase of exposure time. Then, a clear tendency was not observed for AC according to exposure time (Okajima et al. 2005, Qu et al. 2009).

The presence of oxygenated polar groups was reported by Sellin and Campos (2003) in polypropylene films with the use of corona treatment. The main groups were $\mathrm{C}=\mathrm{O}, \mathrm{C}-\mathrm{O}$ and $\mathrm{COH}$.

There are some treatments that are similar to corona treatment (electric discharge) and may be associated with corona, but these involve specific conditions (pressure, reactors, controlled atmosphere and temperature) which are different from the corona treatment. In this sense, Tang et al. (2007) using radiation and oxygen plasma, reported the existence and formation of functional groups $\mathrm{C}-\mathrm{O}, \mathrm{C}=\mathrm{O}$ and $\mathrm{COO}-$, which were formed on the surface of activated carbons undergoing this treatment.

Corroborating the findings of this study, Zhang et al. (2012) studying the influence of electric discharges on activated carbon, concluded that the treatment promotes the increase of surface acid groups. Vignesh et al. (2016) reported the increase of oxygen functional groups on the surface, mainly carboxyl groups with plasma treatment.

FOURIER TRANSFORM INFRARED SPECTROSCOPY (FTIR)

The spectra of treated and non-treated activated carbons are presented in Figure 2. According to the spectra, there are basically two main bands that feature activated carbons according to molecular vibration. The band at $3500 \mathrm{~cm}^{-1}$ corresponds to
O-H stretching, principally of carboxylic acid functional group. The band at 1600-1700 $\mathrm{cm}^{-1}$ corresponds to $\mathrm{C}=\mathrm{O}$ stretching in carboxylic acid or lactone in phenolic groups.

Observing the spectrum, it is not possible to affirm that there are changes in the bands at 3500 and $1600-1700 \mathrm{~cm}^{-1}$ since these bands are influenced by water presence. Furthermore, the changes occurred only on surface, it being hard to observe the groups formed and the differences. However, a slight alteration at $1300 \mathrm{~cm}^{-1}$ is observed and this may correspond to $\mathrm{OH}$ from carboxylic acid and secondary alcohols.

According to Che et al. (2013) who used plasma dielectric discharge under $\mathrm{N}_{2}$ atmosphere, the FTIR analysis of treated carbons showed different bands relative to a non-treated activated carbon spectrum, suggesting that there was addition of new atoms and new structures in the activated carbon structure. Qu et al. (2013) in a similar study, showed the principal bands correspond to $\mathrm{O}-\mathrm{H}$, $\mathrm{C}-\mathrm{H}$ and $\mathrm{C}=\mathrm{C}$ bonds at 3500,2900 and $1600 \mathrm{~cm}^{-1}$, respectively. Zhang et al. (2016b) using nonthermal plasma treatment observed changes between the treated (exposure time) and non-treated activated carbon. The bands were 1080, 1440, 1580 and 1710 $\mathrm{cm}^{-1}$ corresponding to $\mathrm{C}=\mathrm{O}$ and $\mathrm{C}-\mathrm{O}$ stretching being assigned to oxidation caused by treatment.

\section{ELEMENTAL ANALYSIS}

Percentage of each element and the oxygen ratio is showed in Table III. According to this table, there are differences in element percentage and Oxygen/ Carbon ratio among treatments. It can be seen that the oxygen content increases with treatment, while the other elements do not follow a tendency. Comparing non-treated AC (T1) and the higher exposure time (T5), there was a $1.92 \%$ increase in oxygen content. This is explained by the oxidation occurred in the activated carbon surface and the creation of new functional groups during treatment. 


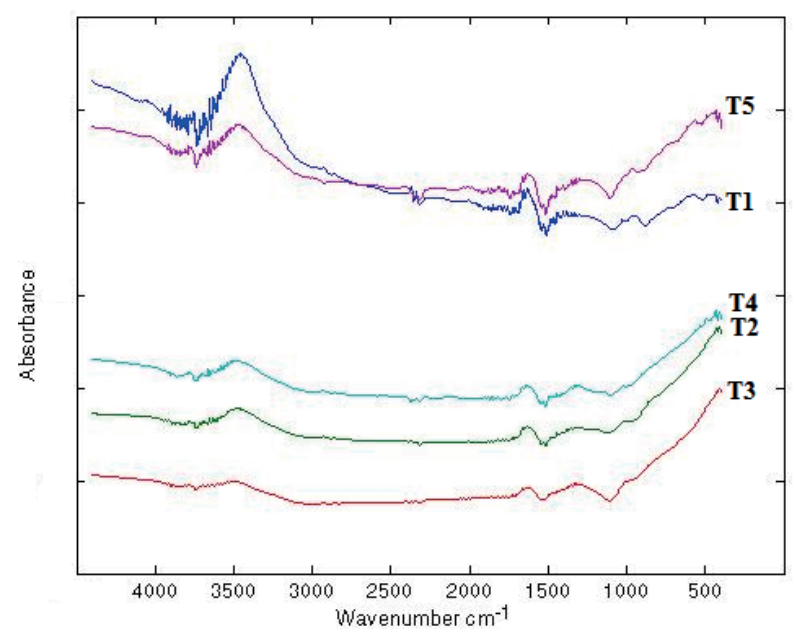

Figure 2 - FTIR spectrum from activated carbons T1 (nontreated) and T2, T3, T4 and T5 (treated).

TABLE II

Quantity of functional groups according to treatments.

\begin{tabular}{lccc}
\hline \multirow{2}{*}{ Treatment } & \multicolumn{3}{c}{ Functional groups $\left(\mathbf{m m o l ~ g}^{-1}\right)$} \\
\cline { 2 - 4 } & $\begin{array}{c}\text { Carboxylic } \\
\text { acid }\end{array}$ & Lactone & Phenol \\
T1 (0 min) & 0.8344 & 0.1510 & 0.0352 \\
T2 (2 min) & 0.8647 & 0.1241 & 0.0045 \\
T3 (5 min) & 0.9034 & 0.1227 & 0.0075 \\
T4 (8 min) & 0.8669 & 0.1484 & 0.0216 \\
T5 (10 min) & 0.9142 & 0.1163 & 0.0179 \\
\hline
\end{tabular}

Oxygen content follows an increasing tendency and this can be related to the increased exposure time. Thus, at higher exposure times the electric discharge caused intense surface modifications. Carbon content decreases, especially, comparing T1 and T5 (1.99\%). This confirms that electric discharge increased the oxygen content and decrease the carbon content in activated carbon, as reported by Zhang et al. (2015). The authors using non-thermal plasma treatment got an increase of $2.14 \%$ in oxygen content and decrease of $2.35 \%$ in carbon content.

Oxygen content is related to the functional groups and acidity present on the surface, since the main functional groups have oxygen in their structures. Thus, the increasing oxygen content may be related to the carboxyl acid increase and consequently the acidity increase. Decrease of carbon content can be related to chemical reactions performed in AC surface by oxidation. During surface oxidation, molecular modification can occur and consist of adding of oxygen atoms (new functional groups formation) or rupture of AC structures (Ding et al. 2014).

The $\mathrm{O} / \mathrm{C}$ ratio presented an increasing tendency as well as oxygen content. The high $\mathrm{O} / \mathrm{C}$ ratio can suggest that there were a high number of radicals which culminate in the formation of new functional groups on the surface. Oxygen functional groups can affect adsorption process, mainly from molecules of different chemical structure, such as polarity. Both structure (functional group) and amount of oxygen on surface impact adsorption of polar molecules. Besides, changes in amount of oxygen can impact adsorption mechanism of a molecule (Rodriguez-Reinoso et al. 1992).

\section{PROXIMATE ANALYSIS}

Percentage of proximate chemistry of AC are shown in Table IV. Ash content was approximately 5\% in all $\mathrm{AC}$ and does not differ between treatments. An increasing and decreasing tendency is observed for volatile and fixed carbon content in function of treatment, respectively. This difference is due surface oxidation caused by corona equipment. Volatile and fixed carbon content can be related to the amount of carbon and oxygen of AC as reported in elemental analysis (Table III), since the main volatile matters are composed by oxygen atoms in its structure, mostly on the surface (Dinh et al. 2016) and fixed carbon are composed by carbon layers in AC structure (Marsh and Reinoso 2006). Then, treated activated carbon are different from no-treated AC in proximate chemistry. Besides, volatile and fixed carbon content were dependent on exposure time to corona treatment, as well as other properties reported in this study. 
TABLE III

Elemental analysis of each treatment.

\begin{tabular}{|c|c|c|c|c|c|}
\hline \multirow{2}{*}{ Treatment } & \multicolumn{4}{|c|}{ Element (\%) } & \multirow{2}{*}{$\begin{array}{l}\mathbf{O} / \mathrm{C} \\
(\%)\end{array}$} \\
\hline & Carbon & Hydrogen & Nitrogen & Oxygen & \\
\hline $\mathrm{T} 1$ (0 min) & 78.62 & 1.28 & 0.33 & 19.77 & 25.15 \\
\hline $\mathrm{T} 2$ (2 min) & 79.36 & 1.50 & 0.32 & 18.81 & 23.70 \\
\hline $\mathrm{T} 3(5 \mathrm{~min})$ & 78.40 & 1.48 & 0.30 & 19.82 & 25.28 \\
\hline $\mathrm{T} 4$ (8 min) & 78.32 & 1.41 & 0.26 & 20.02 & 25.56 \\
\hline T5 (10 min) & 76.63 & 1.44 & 0.24 & 21.69 & 28.30 \\
\hline
\end{tabular}

\section{THERMOGRAVIMETRY (TGA)}

Thermogravimetry analysis is presented in Figure 3 . It is possible to observe the degradation profiles of treated and non-treated activated carbons. This analysis allows evaluating the thermal stability subjected to high temperatures and the degradation of some structures according to temperature.

According to Figure 3 the different treatments resulted in some differences in the thermal decomposition profiles. Moreover, there are variations in residual mass of different treatments (Table V), treatments T1, T4 and T5 presented higher residual mass, indicating that these treatments were more thermoresistant. Treatments T2 and T3 presented lower residual mass, indicating treatments were less thermoresistant. Besides, these treatments stood out with major differences between the final residual masses. The differences in the degradation profiles may be associated to the presence of the different functional groups on the surface according to treatment (exposure time). During the thermal process, depending on the functional group present, there is formation of different products that can induce higher or lower mass loss, since thermal decomposition of $\mathrm{AC}$ reflect the presence of functional groups on its surface (El-Hendawy 2003). Then, both type and quantity of functional groups affect thermogravimetric curve. However, type of functional groups has greater impact and may explain difference between treatments, because degradation of surface functional groups differs
TABLE IV

Immediate analysis of each treatment.

\begin{tabular}{rcc}
\hline Treatment & Volatile (\%) & Fixed carbon (\%) \\
\hline T1 $(0 \mathrm{~min})$ & 9.01 & 85.96 \\
T2 $(2 \mathrm{~min})$ & 10.19 & 84.77 \\
$\mathrm{~T} 3(5 \mathrm{~min})$ & 10.26 & 84.71 \\
$\mathrm{~T} 4(8 \mathrm{~min})$ & 10.10 & 84.87 \\
T5 $(10 \mathrm{~min})$ & 11.03 & 83.94 \\
\hline
\end{tabular}

from its structure. According to Oliveira et al. (2017), carboxylic acids, carboxylic anhydrides and lactones groups are less stable at around $400{ }^{\circ} \mathrm{C}$. Other surface functional groups (phenol, carbonylic, quinones, and pyrone structures) requires more energy to be degraded (above $400{ }^{\circ} \mathrm{C}$ ). Therefore, treatments (T1, T4 and T5) can be more thermal stable due to higher quantity of phenol groups (Table II) than T2 and T3. Lower values of thermal resistance can also be associated to decomposition of carboxylic surface groups and other $-\mathrm{OH}$ groups (Bansal et al. 1988). Moreover, quantity of surface functional groups can also impact thermal degradation.

The first mass loss occurs around $80{ }^{\circ} \mathrm{C}$ for all ACs, and is related to water loss. Activated carbon hygroscopicity can be related to presence of oxygen functional groups, where hydrogen bonds occur between water and surface (RodriguezReinoso et al. 1992). Mass loss of AC at $200{ }^{\circ} \mathrm{C}$ increases in function of oxidation, indicating water affinity of oxygenated surface groups. Also, there 


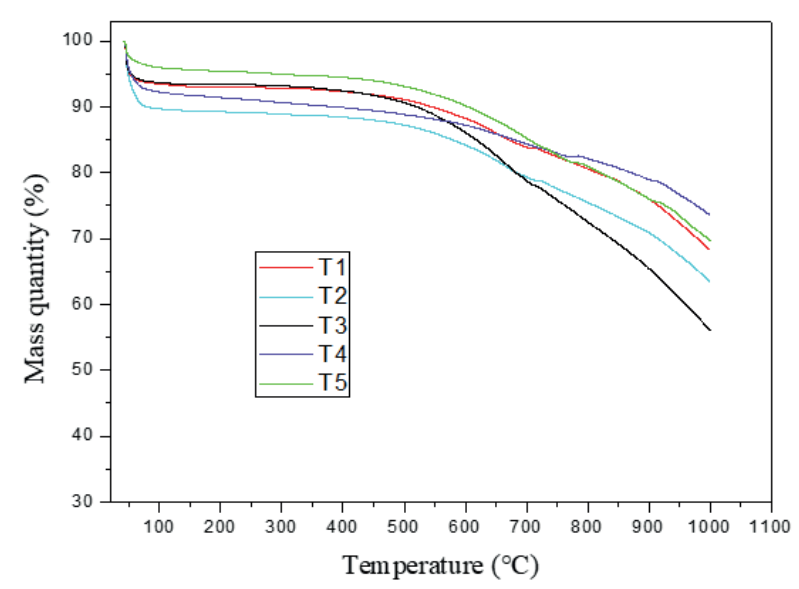

Figure 3 - Thermogravimetric curve of non-treated AC (T1) and respective treatments (T2, T3, T4 and T5), under $\mathrm{N}_{2}$ atmosphere.

TABLE V

Percentage residual masses of each treatment.

\begin{tabular}{cc}
\hline Treatments & Residual Mass (\%) \\
\hline T1 (0 min) & 68.3 \\
T2 (2 min) & 63.2 \\
T3 (5 min) & 55.4 \\
T4 (8 min $)$ & 73.2 \\
T5 (10 min $)$ & 68.9 \\
\hline
\end{tabular}

was a greater mass loss from $550^{\circ} \mathrm{C}$. The mass loss at this temperature can be related to the amount of surface functional groups, by reason of this is the only source of variation between the treatments. According to El-Hendawy (2003), oxygen modified AC lose more mass by up to $500{ }^{\circ} \mathrm{C}$.

Mass loss of some activated carbon structures at temperature above $500{ }^{\circ} \mathrm{C}$, particularly those with carbon and oxygen atoms, can be related to functional group decomposition, especially of lactones, quinones, hydroquinones and phenols present on the activated carbons surface (Araujo et al. 2009).

\section{SURFACE MODIFICATION AND ADSORPTION PROPERTIES}

Surface modified activated carbon from this study was characterized and tested by textural properties and adsorption capacity in a previous published paper. Surface modification was impacted by corona treatment. These results were related to time exposure and completely different to non-treated activated carbon. Surface modified activated carbons were evaluated by adsorption isotherms (cationic and anionic), kinetic adsorption, surface area and scanning electron microscopy. Corona treatment impacted anionic and cationic dye adsorption. Corona treated activated carbons had different behavior on adsorption of these different molecules, due to differences in surface chemistry and textural properties. However, adsorption was negatively impacted (decrease of $25 \%$ to Methylene Blue and 14\% to Congo Red) by corona treatment because of the decay of textural properties. There was difference between treatments in adsorption equilibrium. These differences were due to the superficial modifications of AC. Surface area and porosity was impacted by corona treatment. There was surface area reduction (virgin AC: 525.34 $\mathrm{m}^{2} \cdot \mathrm{g}^{-1}$ and T5: $\left.395.84 \mathrm{~m}^{2} \cdot \mathrm{g}^{-1}\right)$. Scanning electron microscopy showed that pores were destroyed by electric discharge, comparing virgin and treated AC (Pego et al. 2017).

\section{CONCLUSIONS}

In this study, we evaluated the impact of the corona treatment on surface modification of commercial activated carbon. The corona treatment caused surface modification of activated carbons according to exposure time to the electric discharge. This modification occurred due to surface oxidation reactions, especially covalent bonds between $\mathrm{C}$ and $\mathrm{O}$ atoms. The reactions occurred by ionization of gases, making the surface more reactive. Generally, treated activated carbon had more acidity, higher 
quantity of carboxyl acid, oxygen and volatile content, $\mathrm{O} / \mathrm{C}$ ratio and less lactone, phenol, carbon and fixed carbon content. There were differences in molecule vibrational energy, thermal decomposition profiles and residual masses due to the new surface groups according to treatment. Surface modification can improve the activated carbon capacity to adsorb specific substances, because the surface chemistry is the principal factor that impacts adsorption. Corona treatment can be a new method for surface modification of activated carbon and may improve specific adsorption capacity of activated carbon. New studies aimed towards the impact of corona treated activated carbon on adsorption process are required and need to be conducted with different adsorbents and conditions. Corona treatment may be used in wood and other lignocellulosic materials to change properties.

\section{ACKNOWLEDGMENTS}

This research was founded by Coordenação de Aperfeiçoamento de Pessoal de Nível Superior (CAPES) - Brazil and the Wood Science and Technology Postgraduate Program. Authors thank the Department of Chemistry at the Universidade Federal de Lavras.

\section{AUTHOR CONTRIBUTIONS}

Matheus was the main author of the study, being present in all phases of elaboration. Maria was the project leader, also participating in all phases. Janaina contributed to writing and data analysis. Tais contributed to experiment and writing.

\section{REFERENCES}

AGUIAR CRL, FONTANA É, VALLE JAB, SOUZA AAU, MORGADO AF AND SOUZA SMAGU. 2016. Adsorption of Basic Yellow 28 onto chemically-modified activated carbon: Characterization and adsorption mechanisms. Can J Chem Eng 94: 947-955.

ARAUJO DM, YOSHIDA MI, STAPELFELDT F AND AMBIENTAL E. 2009. Estudos comparativos entre carvão ativado e resina de troca iônica para adsorção de ouro , cobre e ferro. R Esc Minas 62: 463-468.

ASTM. 2007. D-1762-64: Standard test method for chemical analysis of wood charcoal. West Conshohocken, 2 p.

BANSAL RC, DONNET JB AND STOECKLI F. 1988. Active Carbon. New York: Marcel Dekker, 482 p.

BOEHM HP. 1994. Some aspects of the surface chemistry of carbon blacks and other carbons. Carbon 32: 759-769.

BRZEZIŃSKI S, POŁOWIŃSKI S, KOWALCZYK D, KARBOWNIK I AND MALINOWSKA G. 2009. Effect of the corona discharge treatment of polyester fabrics on their adhesive properties. Fibres Text East Eur 75: 98-102.

CAO H, XING L, WU G, XIE Y, SHI S, ZHANG Y, MINAKATA D AND CRITTENDEN JC. 2014. Promoting effect of nitration modification on activated carbon in the catalytic ozonation of oxalic acid. Appl Catal B Environ 146: 169-176.

CARVALHO J, BORGES WM, CARVALHO M, ARANTES AC AND BIANCHI ML. 2017. Bagasse as a Source of Glucose: Corona Pretreatment. Rev Virtual Química 9: 97-106.

CHE Y, ZHOU J AND WANG Z. 2013. Plasma Modification of Activated Carbon Fibers for Adsorption of SO2. Plasma Sci Technol 15: 1047-1052.

DING L, WANG L, SHAO L, CAO J AND BAI Y. 2014. The water-dependent decay mechanism of biaxially-oriented corona-treated polyethylene terephthalate films. RSC Adv 4: 54805-54809.

DINH TV, CHOI IY, SON YS, SONG KY, SUNWOO Y AND KIM JC. 2016. Volatile organic compounds (VOCs) in surface coating materials: Their compositions and potential as an alternative fuel. J Environ Manage 168: 157-164.

EL-HENDAWY ANA. 2003. Influence of HNO3 oxidation on the structure and adsorptive properties of corncob-based activated carbon. Carbon 41: 713-722.

GE X, MAX, WUZ, XIAO XAND YAN Y. 2015. Modification of coal-based activated carbon with nitric acid using microwave radiation for adsorption of phenanthrene and naphthalene. Res Chem Intermed 41: 7327-7347.

GONG Z, LI S, MA J AND ZHANG X. 2016. Self-flocculated powdered activated carbon with different oxidation methods and their influence on adsorption behavior. $\mathrm{J}$ Hazard Mater 304: 222-232.

GOSCIANSKA J, MARCINIAK M AND PIETRZAK R. 2015. The effect of surface modification of mesoporous carbons on Auramine-O dye removal from water. Adsorption 22: 1-10.

HOUSHMAND A, DAUD W AND SHAFEEYAN M. 2011. Tailoring the Surface Chemistry of Activated Carbon by NitricAcid: Study Using Response Surface Method. Bull Chem Soc Jpn 84: 1251-1260.

HOUSHMAND A, SHAFEEYAN MS, ARAMI-NIYAAAND DAUD WMAW. 2013. Anchoring a halogenated amine on the surface of a microporous activated carbon for carbon dioxide capture. J Taiwan Inst Chem Eng 44: 774-779. 
JARAMILLO J, ÁLVAREZ PM AND GÓMEZ-SERRANO V. 2010. Preparation and ozone-surface modification of activated carbon. Thermal stability of oxygen surface groups. Appl Surf Sci 256: 5232-5236.

KOSTOV KG, NISHIME TMC, HEIN LRO AND TOTH A. 2013. Study of polypropylene surface modification by air dielectric barrier discharge operated at two different frequencies. Surf Coatings Technol 234: 60-66.

MARSH H AND RODRÍGUEZ-REINOSO F. 2006. Activated Carbon. London: Elsevier, 536 p.

OKAJIMA K, OHTA K AND SUDOH M. 2005. Capacitance behavior of activated carbon fibers with oxygen-plasma treatment. Electrochim Acta 50: 2227-2231.

OLIVEIRA G, ANDRADE R, TRINDADE M, ANDRADE H AND CARVALHO C. 2017. Thermogravimetric and spectroscopic study (TG-DTA/FT-IR) of activated carbon from the renewable biomass source babassu. Quim Nova 40: 284-292.

PEGO MFF, CARVALHO J, BORGES W AND BIANCHI ML. 2017. Impact of Corona Treated Activated Carbon in Anionic and Cationic Dye Adsorption. Cerne 23: 219-228.

QU GZ, LI J, LIANG DL, HUANG DL, QU D AND HUANG YM. 2013. Surface modification of a granular activated carbon by dielectric barrier discharge plasma and its effects on pentachlorophenol adsorption. J Electrostat 71: 689-694.

QU GZ, LU N, LI J, WU Y, LI GF AND LI D. 2009. Simulataneous pentachlorophenol decomposition and granular activated carbon regeneration assisted by dielectric barrier discharge plasma. J Hazard Mater 172: 472-478.

RODRIGUEZ-REINOSO F, MOLINA-SABIO M AND MUÑECAS MA. 1992. Effect of microporosity and oxygen surface groups of activated carbon in the adsorption of molecules of different polarity. J Phys Chem 96: 27072713.

SELLIN N AND CAMPOS JSDC. 2003. Surface composition analysis of PP films treated by corona discharge. Mater Res 6: 163-166.

SHAFEEYAN MS, DAUD WMAW, HOUSHMAND A AND SHAMIRI A. 2010. A review on surface modification of activated carbon for carbon dioxide adsorption. J Anal Appl Pyrolysis 89: 143-151.

SHAFEEYAN MS, HOUSHMAND A, ARAMI-NIYA A, RAZAGUIZADEH H AND DAUD W. 2015. Modification of Activated Carbon Using Nitration Followed by Reduction for Carbon Dioxide Capture. Bull Korean Chem Soc 36: 533-538.

STEPCZYÑSKA M. 2015. Analysis of the decay of some effects of modification of polylactide surface layers. Polimery 60: 462-467.

TANG S, LU N, WANG JK, RYU SK AND CHOI HS. 2007. Novel Effects of Surface Modification on Activated Carbon Fibers Using a Low Pressure Plasma Treatment. J Phys Chem C 111: 1820-1829.

VIGNESH K, VIJAYALAKSHMI KAAND KARTHIKEYAN N. 2016. Impact of Plasma Surface Treatment on Bamboo Charcoal/Silver Nanocomposite. Surf Rev Lett 23: 1550089.

YANG S, LI L, XIAO T, ZHENG D AND ZHANG Y. 2016. Role of surface chemistry in modified ACF (activated carbon fiber)-catalyzed peroxymonosulfate oxidation. Appl Surf Sci 383: 142-150.

ZHANG B, XU P, QIU Y, YU Q, MA J, WU H, LUO G, XU M AND YAO H. 2015. Increasing oxygen functional groups of activated carbon with non-thermal plasma to enhance mercury removal efficiency for flue gases. Chem Eng J 263: 1-8.

ZHANG D, HUO P AND LIU W. 2016a. Behavior of phenol adsorption on thermal modified activated carbon. Chinese J Chem Eng 24: 446-452.

ZHANG J, DUAN Y, ZHOU Q, ZHU C, SHE M AND DING W. 2016b. Adsorptive removal of gas-phase mercury by oxygen non-thermal plasma modified activated carbon. Chem Eng J 294: 281-289.

ZHANG YZ, ZHOU W, HAN Y, XIONG XY AND ZHANG Y. 2012. Influence of Pulse Discharge on Pore Structure and Surface Properties of Activated Carbon. Energy Procedia 16: 1886-1890.

ZHOU H, ZHEN W, ZHU Q, WU X, CHANG Z AND LI W. 2015. Role of the surface chemistry of activated carbons in dye removal from aqueous solution. Int J Miner Metall Mater 22: 770-776. 